\title{
Trayectorias de vida, trayectorias políticas: ejercicios situados de política encarnada ${ }^{1}$
}

\section{Gabriela Montiel*}

\section{Recibido: julio de 2016 / Aceptado: agosto de 2016}

Trayectorias de vida, trayectorias políticas: ejercicios situados de una política encarnada, es una invitación a repensar la política y lo político ubicando como pauta de enunciación los cuerpos. Corporalidades que no se configuran a solas, sino que son atravesadas constantemente por discursos de poder (orden, alimentación, belleza, deseo, movilidad, agencia, subordinación, represión). Esta tesis la fuimos tejiendo mediante la narrativa de vida de la mano del Método Biográfico (Sautu, 2004), la propuesta de investigación feminista del Conocimiento Situado (Haraway, 1989) y en cuanto al cuerpo teórico para el análisis concretamente la línea de reflexión desde los Feminismos decoloniales en relación a las identidades políticas y movimientos sociales (Flórez, 2010) y el Transfeminismo (Álvarez Castillo, 2014; Preciado, 2013; Solá, 2013; Sentamans, 2013). ¿Qué implica encarnar la política? Responder a esta pregunta es el objetivo a lo largo de este diálogo entre tres compañeras artistas y mi persona, posicionando este cuerpo situado como principal pauta de enunciación.

Palabras clave: cuerpo-arte / política

\section{Trayectorias de vida, arte y cuerpo}

El punto de partida en esta investigación es el cuerpo, espacio desde el cual se desarrollan ejercicios autoreflexivos y se teje el diálogo con otras corporalidades, espacios/lugares y discursos hegemónicos. El cuerpo se ubica como el lugar desde el

1 Ensayo ganador de la primera edición del Premio de Investigación Roberto Guibernau, coordinado por el Instituto de Historia de Nicaragua y Centroamérica - IHNCA de la Universidad Centroamericana - UCA.

* Programa Interdisciplinario de Estudios de Género (PIEG) del departamento de Ciencias Sociales, Universidad Centroamericana -UCA. Managua, Nicaragua. Correo electrónico: gabrielamontiel13@gmail.com 
Encuentro No. 104, 29-37, 2016

cual enunciar y posicionar la propia voz, esa que le permite a quien enuncia nombrar su realidad y configurar sentidos desde su experiencia encarnada. Este acto en sí mismo, potencia.

La configuración de sentidos en este caso concreto es sobre la política y lo político. Perfilando la política concretamente como los discursos, estructuras y espacios asignados históricamente a esta práctica; y lo político aquello que se nombra como tal. Ante la política se posiciona una crítica concreta desde las narrativas de vida y los planteamientos provenientes del Conocimiento situado (Haraway, 1989), el Feminismo decolonial (Flórez, 2010); así como del proyecto concreto del Transfeminismo. La propuesta metodológica centrada en la experiencia de quién narra es una pauta política, pero también es proceso situado de colectivización de conocimiento, es decir, de entrada es importante mencionar que esta tesis es un ejercicio situado en sí mismo, contaminado por la subjetividad de las voces y corporalidades involucradas en este proceso de diálogo. No buscamos representar otras/todas las realidades.

Entrelazadas con la categoría cuerpo están las narrativas de vida, esas historias que he nombrado en este texto trayectorias de vida: trayectorias políticas. Metodológicamente se dialoga desde la propuesta del Método Biográfico (Sautu, 2004), que se sostiene por el relato que hace en primera persona la entrevistada. En este caso ese relato se concentró en narrar las reflexiones desarrolladas a lo largo de entre tres y cinco años de trabajo autoetnográfico en las trayectorias de las tres compañeras artistas.
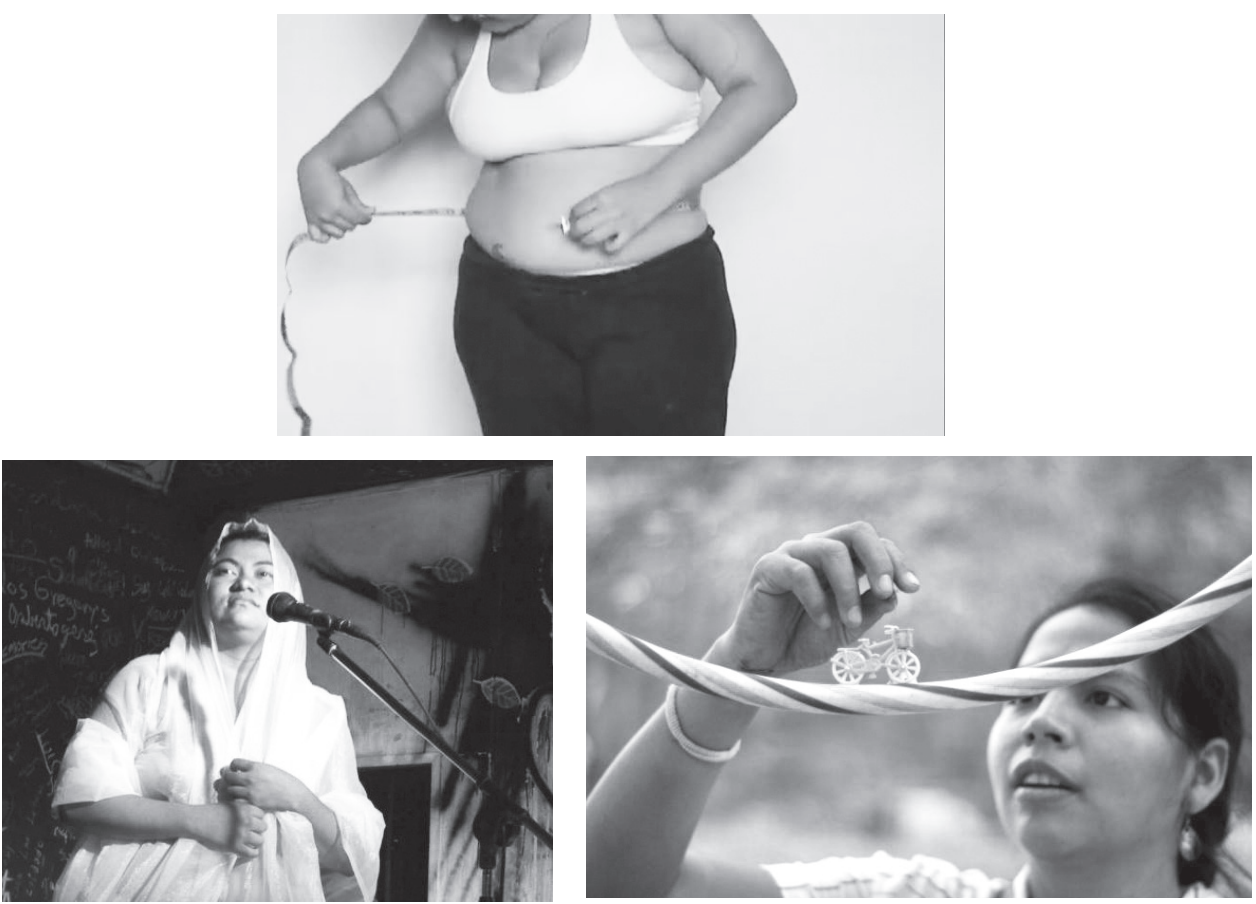

Nota: Las fotografías corresponden a las tres artistas con las que se trabajó esta investigación: María Félix Lotz, Sarahí Mendoza y Darling López. 
La primera trayectoria es la de María Féliz Lotz, que ha desarrollado procesos investigativos y artísticos situando el cuerpo en el centro y concretamente sobre la gordura/el peso, la relación con la comida, los ritmos de vida, discursos de belleza impuestos a los cuerpos de las mujeres. El lenguaje audiovisual es parte de los vehículos que ha utilizado para comunicar y el arte ha sido la metodología de pensamiento que le ha permitido pensar-se más allá de los esquemas cerrados que el sistema impone y enseña. El arte y el feminismo se presentan como sus principales anclajes discursivos y de análisis sobre su realidad.

En la segunda trayectoria encontramos a Sarahí Mendoza, quién a través de la narración oral, el teatro y la poesía recorre su corporalidad y su memoria en el pueblo de Villa Libertad en Somoto, junto a su madre, su padre y las mujeres que habitan ese espacio. Aborda el amor romántico, la gordura y el peso de la estética impuesta y la religión en la vida de las mujeres. Ha politizado su historia, que a la vez es historia colectiva; voz y cuerpo han transmutado de ser espacios configurados para la sumisión, a ser herramientas políticas que enunciar con rabia y también con dolor los múltiples procesos que atraviesan su corporalidad configurada desde los discursos de género.

La tercera trayectoria es la de Darling López, quien se ha interesado en trabajar procesos de investigación situada sobre los espacios. El espacio íntimo, privado y público, y concretamente en los últimos años su proceso artístico se ha instalado en explorar ese espacio público (la calle) a recorrerlo caminando o en bici, encontrando nuevas formas de vincularse con los espacios. Un ejercicio investigativo que le ha permitido ir leyendo los procesos de transformación de la ciudad, e ir ejercitando ese diálogo con otras corporalidades, como las de autoridad y concretamente con espacios públicos que se han privatizado por discursos de control social.

Y una cuarta trayectoria es la propia, que busca desde hace algún tiempo destrabar el cuerpo de todos los miedos encarnados, herencia de una matriz de jerarquías y violencias históricas hacia este cuerpo nombrado femenino/mujer. Esta que soy se asume en constante fuga, me asumo desde el cuerpo. Me reapropio de este cuerpo colonizado por discursos perversos de belleza, deseo y poder. Abrazo mi sangre menstrual, esa que demuestra que estoy viva. Abrazo mi cuerpo que muta y esto lo hago en colectividad con otras, no me lo regala el Estado, sino que me lo autogestiono.

Algunas preguntas que podrían surgir: ¿Cómo dialogan los procesos de política encarnada con esa política Estatal? ¿Cómo lee la estructura política formal, estos ejercicios de autoreflexión cuando pasan a un espacio público? ¿Dónde se sitúa el cuerpo en este diálogo concreto? Es en principio un diálogo entre discursos hegemónicos (racistas, machistas, coloniales) y subjetividades que se autoetnografían. La subjetividad entonces se asume como la principal plataforma desde la cual enunciar, denunciar y liberar.

Somos este cuerpo y este cuerpo es lo que somos. Plantear esta idea no sólo hace referencia a nuestra situación material sino que dialoga con la subjetividad construida individual, colectiva e históricamente, esa que en palabras de Flórez (2010) viene a ser: "una categoría que da sentido a lo que somos y evidencia el carácter interpretativo del ser humano” (2010, p. 173). 
Me parece una categoría útil para pensar las narraciones de estas trayectorias de vida, como esos procesos de significación y sentido que se producen permeados por la vivencia encarnada de lo social en todas sus dimensiones. Si se vivencia y evidencia la política desde la subjetividad, se rompe con los preceptos de esa política tradicional anclada en el pensamiento liberal que consiste en una serie de principios que homogenizan la vida de la gente, universalizan la realidad y establecen por lo mismo un diálogo y soluciones esencialistas.

La política tradicional está compuesta por una serie de principios heredados del pensamiento político liberal de la ilustración, y esto desde diversos puntos es complejo. Se piensa desde la universalidad, es decir, hacemos política que habla por un todo (el pueblo, la nación, la ciudadanía). Se piensa en una política que es neutra, es decir, que no responde a intereses particulares sino a intereses de un común bastante abstracto en el discurso. Tenemos el principio de abstracción, que plantea discursos políticos sobre ciudadanos en general - nicaragüenses, mujeres, hombres - cuando cada cuerpo, aun compartiendo situaciones con otros, se resiste por su propia mutabilidad a ser contenido en un discurso de representación. Es casi como si a esa multitud de rostros se le quisiera encorsetar en ropa de talla XS; no se puede y si se intenta es asfixiante.

Sobre esta lógica de la abstracción Ciriza (2012, p. 14) plantea que "la lógica de la abstracción habilita la cosificación del cuerpo, pero también la asignación de derechos a entes físicos-metafísicos que en modo alguno son sujetos humanos”. Es una postura política asumir desde qué lógicas dialogamos cuando vivimos política, desde lo palpable o lo distante al cuerpo.

Esta tesis reconoce la necesidad de reconocer que la política, como pensamiento y práctica, es un proceso encarnado. Mariana Chaves (2004) escribe: "hay política porque hay cuerpo", por lo tanto lo político será todo aquello que atraviesa ese cuerpo y que luego necesitará devenir en política, que sea encarnada. Desde diversos ejercicios de investigación feminista se han señalado contradicciones y tensiones con un discurso político liberal que empaqueta las vidas de la gente en ciudadanías del tipo Cajita Feliz: un combo con pocas opciones y pensado para un consumo de masas. Alejandra Ciriza señala que la teoría feminista ha insistido en la relación entre cuerpo real y orden social respecto de las relaciones de subordinación existentes que afectan, entre otros grupos, a las corporalidades denominadas mujeres (2012, p. 3).

Es la tensión entre una corporalidad situada y un sujeto político en abstracto: entre una mujer-negra-lesbiana-gorda y las categorías mujeres. Desde esta tensión se estimulan procesos de sospecha ante una política tradicional irreal, y la búsqueda por configurar políticas que se sitúen en el propio cuerpo, historia y cotidianidad.

Es aquí donde la subjetividad es central porque es una potencia de acción cuando la nombramos y la asumimos, como cuando decimos en espacios de autodefensa feminista "mientras menos estemos en los espacios, más violentos van a ser", es asumir este cuerpo con todos esos discursos y violencias que lo atraviesan, y a partir de ahí subvertir esa configuración en potencia, sobre todo colectiva. Reconocer y asumir la propia subjetividad conlleva a reconocer otras subjetividades y poder entonces "organizar la rabia, organizar la rebeldía".

Es como plantea Flórez (2010, p. 182): "La subjetividad también resulta del 
impulso del sujeto a subvertir las estructuras, en este punto la agencia entra en tensión con la estructura...la búsqueda de otras formas de experimentar la identidad siempre se lleva a cabo dentro de unas limitadas condiciones materiales y simbólicas". Son estas trayectorias, y estos ejercicios políticos encarnados una apuesta por construir posibilidades incluso estando inmersas en el terror instaurado en estos cuerpos que somos

\section{2. ¿Qué implica encarnar la política?}

Asumir la política como una vivencia encarnada y lo político como todo lo que atraviesa esa corporalidad implica poner en cuestionamiento las categorías tradicionales desde las que se piensa y se hace política. Desde el feminismo se han venido desmontando una serie de suposiciones: primero fue el género y, parafraseando a Simone de Beauvoir, decimos no nacemos mujeres, nos hacen en el camino... pero luego nos encargaremos de perforar esa identidad liberándonos de su peso. Es decir, la sospecha y la subversión surgen como herramientas políticas situadas desde las cuales se perforan los discursos identitarios de la política liberal.

Sospechar de las categorías es, en principio, reconocer que no son naturales sino construidos por matrices de pensamiento históricamente hegemónicos. Constanza Álvarez (2014, p. 41) desde su ejercicio transfeminista propone "dejemos en claro, ningún concepto es "natural", todos han sido construidos por procesos categoriales y responden a constructos socialmente edificados".

Encontramos en las trayectorias de vida un cuestionamiento compartido sobre la imposición de discursos a nivel social, concretamente centrado en el pensamiento único que lo ubica tanto en la educación formal como en la dinámica de los movimientos sociales. Este cuestionamiento compartido aparece como el primer reto de las trayectorias: desaprender ese pensamiento único y, mediante la metodología del arte como disciplina, ampliar el marco de lectura de la realidad, lo que las lleva a sospechar de los grandes discursos y asumir la corporalidad y los ejercicios autoreflexivos como la principal pauta de conocimiento. Es decir, asumen el ejercicio de autogestionar-se conocimiento y aprendizaje, lo cual rompe con tradiciones de pensamiento social y político.

Este aprendizaje autogestionado, sumado al diálogo con el marco de reflexión de los feminismos, configuran ejercicios políticos situados en las trayectorias presentadas en la tesis. Retomando la consigna de lo personal es político, se trata entonces de asumirlo de forma radical, de irrumpir esa política tradicional y evidenciar sus orificios, para entonces mostrar lo desinflada que ha estado siempre la narrativa política liberal.

El reapropiarse de la propia subjetividad, de esa voz que necesita enunciar, del cuerpo que quiere movilizarse y digerir conflictos, y del espacio que quiero resignificar desde mi propia vivencia, son las principales líneas de búsqueda de las trayectorias de vida. Mafe lo plantea como "dejarse ir", sintiendo el propio pulso. La creatividad posibilita la liberación de un cuerpo socializado por un orden de género que obstaculiza a las mujeres crear-se sus propias narrativas.

Pasar de lo abstracto a lo situado permite dialogar desde los propios marcos de existencia e interpelar todo aquello que quiera absorber esa vida en paquetes de 
masas. Por lo mismo, se cuestiona la política Estatal que se alimenta de la política liberal de la ilustración y de procesos para nada democráticos. Pero también se cuestionan discursos, lógicas y estrategias de las $\mathrm{ONG}$ por su vínculo peligroso con las agendas de la cooperación internacional desde la década de los 90, y concretamente al movimiento feminista se interpela desde sus encuadres heredados de la política liberal.

La base del pensamiento político liberal encapsula ciudadanías, las empaqueta como mercancía y esta tradición de pensamiento político también está presente en la práctica de los movimientos sociales, herederos de una tradición política de los años sesenta y setenta. Se cuestiona una forma de leer la realidad desde un lente, que permite entonces condensar esa realidad para luego poder darle una respuesta concreta. Mafe comparte: "ahora me siento más cómoda desde el arte que desde el feminismo... entender las cosas desde otros enfoques... que las cosas no son $\mathrm{A}+\mathrm{B}$ es C”.

Parte de la crítica se asienta en la necesidad de quebrar imaginarios políticos que posicionan formas o fórmulas validadas de hacer política y desestiman otras, cuestionando en concreto las lógicas identitarias. A esto Constanza Álvarez (2014) lo denominaría "la transición entre una política de Identidades UNO que se auto contiene en su propia definición y una política del Devenir que reconoce las experiencias identitarias como procesos abiertos y discontinuos", a lo que Flórez (2010) denominaría sujetxs de fuga: sujtxs que transitan entre la política identitaria y la fuga misma.

Al renunciar a las identidades encerradas en sí mismas, al pensamiento único y a las recetas, nos encontramos en constante transición. El arte parece ser una herramienta que al politizarla posibilita ir reconfigurando sentidos en distintas direcciones: simbólica, material y discursiva. En las tres trayectorias encontramos procesos artísticos que apuntan a configurar discursos y reinventar realidades, empezando por las propias, de cara a establecer procesos comunicacionales que provoquen desde dentro hacia otras subjetividades, y no desde discursos externos y lejanos al cuerpo.

Y es importante señalar que partir del cuerpo no es acomodarse en la individualidad, sino que se trata de explorar la propia vivencia encarnada e identificar el peso de los discursos hegemónicos que atraviesan la vida, que son eminentemente colectivos. Son trayectorias que rechazan asirse a posturas únicas, por lo tanto no se ven a sí mismas como el proyecto político a replicar.

Es central en las trayectorias el diálogo con el conocimiento situado como postura política, ¿dónde estoy parada en relación a otras?, que tiene que ver con nombrar los privilegios, lo cual conecta con asumir de entrada que precisamente por esta situación no podemos hablar en nombre de otras, ni representar a nadie al estilo tutelaje, que ya lo hacen el Estado y sus instituciones. Asumir los alcances de mi mirada, saber que desde aquí no se puede ver el todo, es reconocer los límites de la propia experiencia, lo cual no reconoce la política tradicional que se autopercibe y autodefine desde un lente universal.

Se encuentra presente una apuesta por revolucionar los sentidos y significados de la misma corporalidad como primer espacio a politizar. Pero también se trata de reinventar las relaciones, las concepciones de amor y afectividad, y la misma 
convivencia. Política es aquello que ocurre en el cuerpo (desde esa subjetividad situada), las relaciones que tejemos en colectividad, y esas cotidianidades que recorremos, ya sean espacios o comunidades autogestionadas.

Entre los lenguajes utilizados en estas trayectorias para recodificar los sentidos impuestos y la propia vivencia encarnada hecha política, las tecnologías, lo audiovisual y la palabra/cuerpo surgen como herramientas centrales en este proceso de reinvención simbólica. Esto se relaciona con lo planteado por Miriám Solá (2013) concretamente desde su lectura transfeminista:

A partir de los noventa, las luchas ya no son exclusivamente económicas o por el reconocimiento, sino luchas que incorporan toda una economía subjetiva y simbólica. De ahí la importancia que adquiere la producción de imágenes, el juego de representaciones, la guerrilla de la comunicación, las interrelaciones entre arte y política, el ciberfeminismo como posibilidad de reinventar las identidades a través de las nuevas tecnologías, y todas las estrategias relacionadas con el plano simbólico (campanas gráficas, videos, fotografías, relatos ficticios, performances, diseño de webs, blogs), anudadas con el deseo de construir nuevas representaciones propias de la realidad (2013, p. 21).

Es en este contexto en el que se sitúan los ejercicios de política encarnada que las compañeras comparten en sus narrativas. Una política que se sitúa en sus marcos materiales y sobre todo subjetivos, un ejercicio político que asume la tarea de reconfigurar los sentidos aprendidos e impuestos en las distintas dimensiones, empezando por la corporalidad, "desde dónde unx dialoga y se vive en el mundo".

El situarse desde esta postura construye un discurso diferente, que en principio no busca enseñarle algo concreto a la gente sino provocar: "mi obra cuestiona, mi postura política sobre el cuerpo, y está presente en mi obra. Sobre el cuerpo y sobre la vida... no te dice de forma panfletaria como lo diría un afiche de una campaña, porque no es publicidad ni mucho menos pero sí está generando un contenido y una determinada mirada que pasa también por la vida de las otras personas". Se trata de reconocer que es una mirada situada que puede dialogar con otras y reconocerlas, la apuesta es no enseñar a repetir una idea, sino provocar "algo".

El cuerpo, los espacios, la cotidianidad se presentan como las esferas políticas a priorizar, o como esas realidades que urge politizar. Se reconoce que lo que duele en el propio cuerpo puede ser una experiencia compartida con otras corporalidades, como lo plantea Sarahí: “...a veces no solamente te podrís vos por dentro cuando pasan las cosas sino mucha gente que está a tu alrededor”. La misma trayectoria feminista nos ha enseñado que colectivizando la rabia politizamos la propia vida. Por esto es importante nombrar de dónde venimos, la necesidad de geolocalizar la subjetividad y desde ahí poder enunciar con fuerza nuestras políticas encarnadas. Las memorias son parte central de una trayectoria que se asume desde la autogestión política y encuentra sus propias narrativas para nombrar lo que ha vivido y desde ahí poder resignificar su mundo.

Surge como elemento central el recorrido que hace la corporalidad por los espacios y lugares, el cómo se posiciona y lo que vive. En las narrativas estas trayectorias contienen memorias de violencias y resistencias, de libertad y control; y en ese vaivén entre lo uno y lo otro se van construyendo huecos de posibilidades por donde se cuelan la potencias, el juego que el arte posibilita con las estructuras y sus 
Encuentro No. 104, 29-37, 2016

discursos impositivos. El espacio público es entonces una plataforma que necesita recorrerse, vivirse, y para eso el propio cuerpo tiene que mutar, a como lo plantea Darling "no es sólo lo que yo hago con la bici, sino lo que la bici hace conmigo". Y ocurre en un proceso de constante diálogo.

Se trata de repensar la corporalidad y subjetividad desde otros lugares de acción y enunciación, descolocar los miedos y revolucionar esos supuestos que limitan la propia movilidad, tomarse los espacios para narrar lo que duele y poder servir de espejo a las historias de otras, a esa historia y memoria colectiva. Implica recorrer lugares que desde el imaginario social y patriarcal han sido históricamente masculinizados, y romper mediante el movimiento circular de las piernas en la bicicleta con ese muro, con esa frontera. Esas fronteras son materiales y a veces simbólicas, y ante ellas el cuerpo, esa corporalidad mutante de la que habla Luis Manuel González Victoria (2011), se asume y se gestiona como espacio de resistencias, de discursividades que se proponen descolocar las grandes verdades, y reconfigurar los sentidos impuestos por las estructuras. Lo hace mediante lenguajes diversos, nombra la realidad con crudeza e intención visceral, y recorre la cotidianidad irrumpiendo en los imaginarios, esos que se sienten propios y que son colectivos al mismo tiempo.

Los ejercicios de la palabra y autoreflexión sobre la corporalidad que se vive se presentan como mecanismos de politización de ese nudo en la garganta, los conflictos anclados en el cuerpo y las memorias, así como la cotidianidad, que se posicionan junto al propio cuerpo como los espacios políticos palpables desde los que se subvierten realidades y mundos. Es desde estas pautas de enunciación: cuerpo, palabra, cotidianidad (lugares), que entonces nos reapropiamos de espacios, y le damos vuelta a los discursos para generar nuevos marcos de lecturas de nuestras realidades. Asumimos el ejercicio de autogestionarnos libertades y autonomías, que si bien conocen los límites impuestos por las estructuras opresoras, se inventan posibilidades de fuga del aparato de identidades, discursos y violencias.

La potencia de estos ejercicios de política encarnada se amplía cuando entran en diálogo con otras experiencias situadas, por esta razón no es nada extraño que el arte, como propuesta metodológica de investigación e intervención sobre las realidades (cuerpos, discursos y espacios), sea el medio desde donde las trayectorias se posicionan. Y es precisamente el paso hacia la colectividad lo que podría presentarse como un reto en estos diálogos, ¿Cómo se logra colectivizar la reflexión? ¿Cómo subvertimos realidades en colectividades más allá de la tradición de partidos, más allá de las agendas prefijadas de la cooperación, más allá de la fijación con el dinero para hacer cosas?

Todas estas son preguntas con múltiples respuestas. Los ejercicios de política encarnadas expuestos en esta tesis se asumen como situados y por ende no apuntan a representar a nadie, ni a hablar por nadie. Se reapropian de su voz/palabra, de esa corporalidad tan intervenida por las estructuras, y de los espacios. Desde ahí le apuestan a reconfigurar los sentidos impuestos, generando una revolución simbólica y material. Desde el transfeminismo (Álvarez, 2014) como proyecto político los nombraríamos como "procesos abiertos, discontinuos" y desde el Feminismo Decolonial (Flórez, 2010) los nombraríamos procesos políticos e identitarios de fuga.

Por lo mismo, no son ejercicios políticos que puedan ser leídos - y tampoco lo quieren - como una receta a replicar. Lo que sí se puede decir es que en estas trayectorias de vida, la autoreflexión y autoetnografía, el encontrar la propia voz 
desde la cual enunciar, el situarse desde el cuerpo y la autogestión como postura política, han posibilitado una ampliación de su poder. Y cuando lo han colectivizado, ese poder se transforma en potencia colectiva que libera y sana.

Se torna necesario entonces que muchas trayectorias con ejercicios de política encarnada se encuentren y juntxs desestabilicen esos preceptos políticos tan alejados de la vida misma de la gente. Desde los distintos feminismos y concretamente aquellos que se sitúan desde la autogestión "real”, lejos de la lógica de la Cooperación y en constante sospecha y cuestionamiento de la lógica Estatal y Partidista, sabemos que podemos generarnos nuevos marcos de realidad y existencia en medio de tanta violencia. Sabemos que podemos colectivizar el dolor y la rabia y transformarlo en alegría y lucha situada desde nuestras propias historias de vida. Eso para nosotras es política, eso para nosotras es lo político.

Y como dicen las compañeras mexicanas, Las Hijas de la Violencia, que salen a las calles para reapropiarse de esos espacios tan violentos con nuestras vidas, con pistolas de confites y punk feminista para cuestionar el acosos sexual callejero: "Estamos claras que con lo que hacemos no estamos cambiando el mundo, pero estamos seguras que hemos cambiado el nuestro". Nos alejamos entonces de la herencia de los 60-70 en la que el proyecto era tomar el poder para "cambiarlo todo sin cambiar nada", y nos asumimos desde el cuerpo, desde esta vivencia situada, junto a otras, para reconfigurar vida desde lo personal a lo colectivo. Le apostamos a esto que no es política de masas sino Política encarnada.

\section{Referencias bibliográficas}

Álvarez Castillo, C. (2014). La cerda Punk: Ensayos desde un feminismo gordo, lésbiko, antikapitalista y antiespecista. (1 $\left.{ }^{\mathrm{a}} \mathrm{ed}\right)$. Valparaíso, Chile: Trío Editorial.

Chaves, M. (2004). Biopolítica de los cuerpos jóvenes. KAIRÓS, Revista de Temas Sociales. Universidad Nacional de San Luis. Año 8 (14).

Ciriza, A. (2012). Simone de Beauvoir: De la fenomenología del cuerpo a la utopía de la libertad. Revista Nomadias, (16), 11-21.

Esteban, M. L. (2004). Antropología del cuerpo. Barcelona: Ediciones Bellaterra, S.L.

Flórez Flórez, J. (2010). Lecturas Emergentes: Decolonialidad y subjetividad en las teorías de movimientos sociales. ( $1^{a}$ ed.). Bogotá: Pontificia Universidad Javeriana.

González Victoria, L. M. (2011). Artes de acción: Re-significación del cuerpo y el espacio urbano. Cali: Universidad del Valle.

Haraway, D. (1988). Situated Knowledges: The science question in Feminism and the privilege of Partial Perspective. Feminist Studies, 14 (3): 575-599.

Preciado, B. (2013). Decimos revolución. En M. Solá y E. Urko (Comps.). Transfeminismos: Epistemes, fricciones y flujos. (1a ed.). Tafalla, Navarra: Txalaparta.

Solá, M. (2013). Pre-textos, con-textos y textos. En M. Solá y E. Urko (Comps.). Transfeminismos: Epistemes, fricciones y flujos. ( $1^{\text {a }}$ ed.). Tafalla, Navarra: Txalaparta.

Sautu, R. (2004). El Método Biográfico: La reconstrucción de la sociedad a partir del testimonio de los actores. Buenos Aires: Editorial Lumiere.

Sentamans, T. (2013). Redes transfeministas y nuevas políticas de representación sexual (I) diagramas y flujos. En Solá y E. Urko (Comps.). Transfeminismos: Epistemes, fricciones y flujos. (1 $1^{\mathrm{a}} \mathrm{ed}$.). Tafalla, Navarra: Txalaparta. 